\title{
Corpo, política e emoção: feminismos, estética e consumo entre mulheres negras
}

Body, politics and emotion: feminism, aesthetics and consumption among black women

Gleicy Mailly da Silva*

*Universidade Estadual de Campinas - Campinas, SP, Brasil

Em pós-doutoramento (bolsista Fapesp)

gleicysilva@hotmail.com

https://orcid.org/0000-0002-6295-5000 


\title{
Resumo
}

Este artigo busca refletir a respeito do modo como algumas formas recentes de engajamento político de mulheres negras têm articulado relações entre corpo, estética e emoção enquanto aspectos centrais de seus processos de aprendizado e afirmação identitária. Tendo o contexto paulistano como cenário, a pesquisa etnográfica mostra como, por meio de redes de sociabilidade on-line e off-line, experiências coletivas atuam na reformulação de um conjunto de sentimentos, percebidos na partilha de narrativas dramáticas de discriminação racial, produzindo um novo olhar sobre o corpo e sobre a noção de beleza por meio de linguagens estéticas que, por sua vez, ensejam novas dinâmicas de consumo, ao mesmo tempo em que ampliam os sentidos dos feminismos negros. Minha intenção é atentar para a constituição de um sujeito político plural, alinhado com as mídias contemporâneas, que articula mercado e engajamento a uma economia política das emoções, estimulando novos modelos de subjetividade.

Palavras-chave: feminismos negros; estética; consumo; emoções.

\begin{abstract}
This article reflects on how some recent forms of political engagement of black women establish relations between body, aesthetics and emotion as central aspects of their learning process and identity affirmation. By taking the city of São Paulo as a scenario, this ethnographic research demonstrates, by exploring on-line and off-line sociability networks, the role played by the sharing of dramatic narratives of racial discrimination as central collective experiences in the reformulation of a set of sentiments. I argue that these practices produce a novel perspective on both the body and the notion of beauty through aesthetic languages that, in their turn, promote new dynamics of consumption at the same time that they expand the meanings of black feminisms. I propose to examine the constitution of a plural political subject, aligned with the contemporary media, which articulates market and engagement to a political economy of the emotions stimulating new forms of subjectivity.
\end{abstract}

Keywords: black feminisms; aesthetics; consumption; emotions. 


\section{Apresentação ${ }^{1}$}

Pode-se afirmar que homens negros e mulheres negras experienciam o racismo de maneiras diferentes, através das especificidades das dinâmicas de gênero que os circundam. No entanto, há uma contradição própria do discurso colonial de dominação que os atinge da mesma forma, uma vez que se, por um lado, seus corpos constituem historicamente uma fonte erotização e exotização, por outro lado, são ao mesmo tempo excluídos dos padrões de beleza considerados hegemônicos, constituídos e afirmados a partir do corpo branco. Desse modo, a produção estética como ferramenta de combate à discriminação racial tem sido uma questão cara ao ativismo negro.

Entre os anos 1970 e 1980, quando o movimento negro se consolida no Brasil, marcado fortemente pelos movimentos transnacionais de transformação cultural e política que já vinham ocorrendo desde as décadas anteriores - representados, sobretudo, pelas lutas em torno da independência dos países africanos, pela cena musical internacional que deu visibilidade a artistas negros de diferentes nacionalidades e, mais precisamente, pelos movimentos pelos direitos civis, pelo movimento Black Power e o pelo movimento cultural Black is Beautiful, ocorridos nos Estados Unidos -, o questionamento das relações entre corpo e padrões de beleza torna-se central às coletividades negras, promovendo um conjunto diversificado de formas de resistência política por meio da afirmação estética. Nesse período, através de diferentes elaborações culturais, que vão desde os bailes black, protagonizados nas cidades de São Paulo e do Rio de Janeiro, aos blocos afro presentes no carnaval da Bahia, as categorias "orgulho" e "autoestima" ganham importante relevo.

Porém, é no decorrer da década de 1990, particularmente com o lançamento da revista Raça Brasil, que essa dimensão estético-política começa a ser percebida e relacionada a um mercado de consumo de produtos específicos, voltados mais propriamente a uma suposta classe média negra (Kofes, 1996). A partir

1 Agradeço à Fapesp pelo financiamento das pesquisas de doutorado (processo ${ }^{\circ} 2012 / 21321-7$ ), já finalizada, e de pós-doutorado (processo ${ }^{\circ}$ 2018/04929-8), em curso, que dão lugar a este artigo. Lembro que as opiniões, hipóteses e conclusões ou recomendações expressas neste material são de minha responsabilidade e não necessariamente refletem a visão da Fapesp. Agradeço, ainda, às professoras Livia de Tommasi e Heloísa Buarque de Almeida pelas discussões e apontamentos sobre minha pesquisa etnográfica que estimularam as reflexões aqui apresentadas. 
desse período "o poder simbólico e o significado da beleza" (Fry, 2007, p. 316) adquirem maior importância enquanto temas de investigação, uma vez que tais expressões enunciam práticas, discursos e desejos de homens negros e de mulheres negras sobre seus corpos, oferecendo importantes pistas para a compreensão das transformações nas dinâmicas de sociabilidade e de pertencimento identitário. ${ }^{2}$

Com a virada dos anos 2000, um conjunto de transformações político-econômicas se dá no país, impactando particularmente as camadas populares. Nesse cenário de mudanças, quatro aspectos merecem destaque: 1) a ampliação do acesso ao ensino superior, com a intensificação de medidas de ação afirmativa e cotas raciais; ${ }^{3}$ 2) a ampliação das políticas de cultura em nível federal, favorecendo a participação de uma variedade significativa de coletividades e grupos marginalizados que historicamente não constituíam o público-alvo dos financiamentos desse setor (Lima; Ortellado, 2013); 3) o aumento do poder de consumo da população em geral que, embora não incorra de fato em uma mudança social em termos de classe (Pochmann, 2014; Souza, 2012), opera uma mudança significativa no comportamento das camadas populares; e 4) o modo como o consumo e o mercado fortalecem seu lugar enquanto espaços de construção de experiências identitárias de engajamento (Yúdice, 2013) e de reivindicação de cidadania (García Canclini, 2010).

Esse conjunto de transformações atinge, especialmente, jovens negros e negras de camadas populares, os quais ao experienciarem o acesso ao ensino superior, a elevação de seu poder de consumo, bem como a ampliação de políticas públicas para a cultura, se constituem como um novo sujeito de direitos,

2 Não por acaso, parte da literatura nacional sobre relações raciais começa a realçar a relação entre identidade, corpo, estética e política, identificando os cabelos crespos como alvo destacado da discriminação racial e, portanto, um dos mais importantes símbolos de valorização da identidade negra. Conforme ressalta o trabalho pioneiro de Angela Figueiredo (1994), os salões de cabelereiros começam a ser tematizados enquanto espaços alternativos de produção simbólica, de contraposição a representações dominantes sobre a beleza, estimulando pesquisas a atentarem para essas dinâmicas em distintas cidades do país, como Belo Horizonte (Gomes, 2003), São Paulo (Santos, 2000), Rio de Janeiro (Fry, 2007) e Salvador (Figueiredo, 1994, 2002). Desse modo, o tema da estética passa a ser mais amplamente compreendido não apenas como um mero aspecto relativo à aparência, mas como um aspecto estruturante de formas de engajamento político negro.

3 Dados do IBGE revelam que, entre 2004 e 2014, houve um aumento de $16,7 \%$ para $45,5 \%$ de estudantes negros (Negros..., 2016). 
cuja subjetividade irá perpassar experiências culturais, políticas, educacionais, estéticas, afetivas e de consumo de maneiras até então inéditas.

Tais contextos renovados de afirmação identitária e de experimentação política, por sua vez, intensificam o olhar sobre o corpo e a noção de beleza, mas também sobre novas possibilidades de engajamento. Por meio desses processos de reformulação estético-política, a dimensão das emoções adquire um papel central, estimulando a construção de novos espaços de enunciação e de representatividade, bem como de dinâmicas de consumo que irão atuar fortemente na recomposição de formas de subjetividade.

Dando continuidade às investigações desenvolvidas em minhas pesquisas recentes (Silva, 2016, 2018), nas quais analiso as imbricações entre cultura, política e economia a partir da etnografia de um circuito de atividades culturais e comerciais voltadas à comunidade negra na cidade de São Paulo, ${ }^{4}$ considerando a temática deste número da revista, o presente artigo tem como objetivo refletir a respeito do modo como algumas formas recentes de engajamento político de mulheres negras têm articulado relações entre corpo, estética e emoção enquanto aspectos centrais de seus processos de autoafirmação e de aprendizado político.

Para lidar com esse conjunto de questões, organizei o artigo em três partes. Num primeiro momento, a partir da etnografia realizada no ateliê Xongani, uma marca de roupas e acessórios, chamo atenção para o papel das emoções na mediação de uma linguagem de engajamento e de mudança estética, através da qual "sentimentos de desajuste" são desconstruídos coletivamente. Nesse processo, em que as atividades de consumo são traduzidas em experiências estético-afetivas de transformação e afirmadas como uma prática feminista, a moda se torna uma importante ferramenta para a comunicação de processos de mudança cultural e política.

4 Em minha pesquisa de doutorado realizei uma análise etnográfica das redes de relações constitutivas da Feira Preta. Trata-se de uma feira voltada ao comércio de produtos segmentados e à promoção de atividades culturais, criada em 2002, e que tem como objetivo a divulgação de negócios de empreendedores negros e o estímulo a debates sobre temas que relacionam afirmação identitária e dinâmicas de mercado enquanto formas de reivindicação política. Realizada uma vez ao ano, em grandes espaços de exposição como o pavilhão do Anhembi e o Centro de Exposições Imigrantes, a Feira Preta que, desde 2009, é mantida por uma organização social sem fins lucrativos, recebe cerca de 10 mil visitantes a cada edição. 
Atentando para tais processos, num segundo momento, seleciono dois produtos Xongani, comercializados na loja on-line da marca, para refletir sobre os impactos de tais formas de consumo e da construção de novos padrões de representatividade para a autoestima dessas mulheres. Por fim, ao explicitar os encadeamentos entre as narrativas apresentadas no ateliê de moda e tais referências de mulheres negras, representadas através dos acessórios da Xongani, mostro como a categoria empoderamento torna-se relevante para descrever tais processos subjetivos de mudança, constituindo uma experiência de enunciação que, para além do trânsito entre o léxico acadêmico e o da militância, nos permite atentar para a interpenetração de uma lógica econômica que enseja novos discursos em torno da relação entre consumo e feminismo.

\section{Desconstruindo um "sentimento de desajuste"}

Conheci os produtos Xongani na edição da Feira Preta de 2011, em São Paulo. Durante meus três anos de pesquisa de campo do doutorado observei a presença dessa marca em todos os eventos que acompanhei. Nessas ocasiões, seus estandes ficavam abarrotados de mulheres ávidas por conhecer seus produtos e prová-los. Tal popularidade e o fato de a marca pertencer a duas empreendedoras negras que começaram suas atividades como microempresárias foram fatores que despertaram minha atenção, fazendo-me buscar uma aproximação com Ana Paula Mendonça, uma de suas idealizadoras. Após alguns contatos, decidi entrevistá-la. Visitei o ateliê Xongani, localizado próximo à estação Artur Alvim da linha vermelha do metrô, na Zona Leste de São Paulo, no dia 30 de março de 2016 e a narrativa a seguir constitui parte de meus relatos de campo.

Cheguei ao ateliê por volta das $17 \mathrm{~h}$. Enquanto visitava calmamente o espaço, Angela, ${ }^{5}$ uma funcionária, me apresentou a loja. Animada com o fato de eu estar ali por conta de uma pesquisa de faculdade, explicou-me que estava cursando História na universidade e que desejava muito seguir carreira acadêmica. Quando perguntei quais eram seus interesses de pesquisa, a jovem negra,

5 Nome fictício. 
perfeitamente maquiada, com seus cabelos crespos volumosos emoldurando o rosto, e grandes brincos coloridos, aparentando ter não mais do que 20 anos de idade, respondeu convicta: "África, claro! Nossa história."

Então me explicou que as roupas possuíam uma variação maior quanto à numeração, não seguindo os "padrões europeus". Assim, o tamanho "P", por exemplo, era um pouco maior que o padrão encontrado no mercado, de forma que todas as numerações fossem um pouco maiores. Nas palavras de Angela: "Nós negras somos maiores, temos quadris mais largos. Dificilmente uma mulher negra brasileira cabe em um número 38. Por isso fazemos peças em tamanhos que estejam adequados aos nossos padrões." Por se tratar de um ateliê, na falta de alguma peça em um tamanho específico, seria possível encomendar a peça sob medida.

Mal terminei de olhar a primeira arara de vestidos e Ana Paula chegou. Nos cumprimentamos e entramos em seu escritório, onde avistei em sua mesa de trabalho o livro Sejamos todos feministas, da escritora nigeriana Chimamanda Adichie. Ao me ver olhando para o livro, Ana Paula o segurou e disse: "Esse é meu livro de cabeceira”, folheando rapidamente suas páginas, quase inteiramente marcadas com post-its, e devolvendo o livro à mesa.

A trajetória que conduz Ana Paula Mendonça até a Xongani é desenhada pelas linhas de costura de sua mãe, Cristina, que, desde a infância da filha, com uma veia militante e servindo-se da formação em economia doméstica, fazia uso de suas habilidades de costura, bordado e artesanato para confeccionar acessórios para a pequena Ana Paula. A intenção do cuidado com a filha era permitir que Ana Paula pudesse desde cedo participar de todas as atividades escolares sem se sentir constrangida por suas especificidades, atitude que Ana Paula, então com 28 anos de idade, rememorou, durante nossa conversa, como uma forma de afirmação identitária e de proteção.

A Cristina sempre cuidou de mim, sempre criou meus acessórios. O que não cabia, ela fazia. Não cabia a toca da natação, ela fazia. Não cabia a tiarinha do balé, ela fazia. Era a forma que ela tinha de me proteger, de me manter com meu cabelo natural, de me manter com a minha beleza, com a minha ancestralidade. E como ela tinha essa habilidade de criar, ela aproveitava e colocava uma africanidade ali no meio do processo, e era também uma forma dela militar a partir dessas criações. 
Enquanto Ana Paula crescia, sua mãe seguia criando uma série de acessórios, a pedido de amigas e conhecidas, chegando a montar a marca Cris Artes com Tecido para confeccionar, em sua maioria, brincos e colares forrados em tecidos diversos, que vendia em algumas feiras de artesanato, enquanto seguia sua carreira de professora. Até aquele momento, a produção e venda dessas peças era parte de um projeto ainda bastante modesto. Porém, a partir de 2009, dois acontecimentos na vida de Ana Paula estimulam uma virada no entendimento das possibilidades de tais criações: sua entrada na universidade e sua primeira viagem a Moçambique.

Cursando Design de Interiores no Centro Universitário Belas Artes e incomodada em passar seus quatro anos de formação estudando o que definiu como "moda europeia", Ana Paula viajou para a África com seu marido, um estudante moçambicano da Universidade de São Paulo e, ao entrar em contato com os tecidos africanos, começou a vislumbrar outras possibilidades de criação para sua mãe confeccionar. Em 2011, Ana Paula e Cristina apresentaram seus novos produtos na Feira Preta, no Centro de Exposições Imigrantes (Zona Sul de São Paulo), de onde retornaram sem nenhuma peça e com o desejo de ampliarem sua ideia. Com o destaque dos tecidos africanos na criação dos produtos, entre roupas, bijuterias e acessórios para os cabelos, amparadas pelas habilidades manuais de Cristina e o olhar visionário de Ana Paula, decidiram transformar o nome "Cristina Arte com Tecidos" em "Xongani". Expressão de origem changana - língua falada no sul de Moçambique - e que, segundo Ana Paula, significa "se arrumem", "se enfeitem" ou "fiquem bonitas".

Para divulgarem seus produtos, montaram um site de vendas e intensificaram a participação em feiras de artesanato e eventos que articulam militância política e academia, como o Congresso Brasileiro de Pesquisadore(a)s Negro(a) s (Copene) e o Festival Latinidades. O sucesso de vendas impulsionou a criação do canal Xongani Arte com Tecido no YouTube, através do qual Ana Paula começou a criar vídeos semanais com tutoriais de uso dos produtos, entre outros assuntos sobre moda e comportamento. Somando as habilidades da designer nas redes sociais e nos vídeos, pouco a pouco Ana Paula começou a ser procurada por diferentes clientes que configuravam um público específico: "Mulheres negras, de 25 a 35 anos de idade, universitárias, engajadas politicamente."

O aumento nas demandas e o desejo das clientes de conhecer pessoalmente as criadoras da Xongani estimularam a criação de um ateliê aberto ao público. Assim, 
em 2015, o estúdio de criação localizado nos fundos da casa da avó de Ana Paula foi transferido para um espaço mais amplo, situado na mesma rua. Mudança que tornaria a Xongani em um lugar de encontro e de reformulação coletiva dos imaginários sobre o corpo e sobre os sentidos da noção de beleza, ultrapassando os limites do que seria um simples negócio de compra e venda. A partir de então, Ana Paula intensifica a construção de um trabalho, permeado de cuidado e afeto, em torno das demandas de suas clientes, e que se dirigem, em grande medida, ao que ela classifica como um combate a um "sentimento de desajuste".

Quando a gente começa a vender um brinco, por exemplo, tem todo um processo de desconstrução, tipo "ah, mas não combina com sua roupa". Por quê? Qual é a lógica dessa combinação? “Ah, porque eu já estou com muitas estampas." Então tá, mas vamos ver umas referências de mulheres africanas? Elas usam quatro ou cinco estampas. Então, não combina por quê? Aonde começa esse sentimento de desajuste? "Ah, eu não posso usar isso porque minha boca é muito grande." Aí tem o vídeo do batom vermelho [Ana faz referência a um de seus vídeos], que eu não sei se você viu no YouTube? "Ah, não posso usar batom vermelho porque senão eu pareço o Saci Pererê." Ou "eu não posso estar careca porque é feio". Aí eu falo: "Não, mas tem a Lupita!" Então cada produto que a gente faz e vende, vem junto com uma conversa.

Nessa partilha de sentimentos de desajuste, há experiências que se revelam bastante dramáticas, como em casos de mulheres que, após o uso excessivo de produtos químicos de alisamento para os cabelos, ou o abuso no uso de apliques, danificam parte do couro cabeludo, tendo que conviver irremediavelmente com a calvície precoce.

Tem as meninas carecas por opção, o que eu acho muito legal, mas também tem as meninas que ficam carecas de tanto mexer no cabelo. Eu recebo muita cliente aqui careca daqui para a frente [mostrando com a mão a parte frontal da cabeça] de tanto pôr aplique. Então, aqui vira um lugar que ao mesmo tempo é um caminho para elas resgatarem uma certa autoestima. Porque elas se maltrataram

6 Ana Paula faz referência à atriz de origem mexicana e queniana, Lupita Amondi Nyong'o, que ganhou o Oscar de melhor atriz coadjuvante pelo filme Doze anos de escravidão. 
tanto que essa é uma outra questão que faz elas chegarem na Xongani. A maioria chega porque acha essas coisas muito lindas, mas também tem gente que chega porque é a última opção. Aí eu digo: "Vamos tornar essa a melhor opção? Você só não sabia disso, mas essa pode ser sua melhor opção. Você quer usar turbante por causa do problema no cabelo? Veja que tem muita gente que usa por opção e você pode ser assim também, desde que você se empodere dessa moda. Vamos criar sua autoestima a partir disso."

No cerne do sentimento de desajuste, estão presentes experiências de constrangimento, vergonha, sentimento de inferioridade e humilhação. ${ }^{7}$ Nesse processo, chama atenção o "caminho de resgate" enfatizado por Ana Paula, e que consiste em reinterpretar esse conjunto de sentimentos de inadequação e de autodepreciação por meio da busca de referências de mulheres negras que as permitam lançar mão de outros padrões de beleza com os quais possam de fato se identificar. Essa travessia emocional e subjetiva, construída coletivamente, configura um processo que Patricia Hill Collins (1990) denomina como autodefinição e que se dá por meio da luta contra as imagens e definições sociais que oprimem as mulheres negras. Segundo a autora, a busca por espaços de expressão das diferenças para construção de vozes individuais e coletivas, que configuram atos de resistência contra a vitimização e de consciência da importância da imagem pública das mulheres negras, constitui o principal tema do pensamento feminista negro (Collins, 1990, p. 94).

No esforço para compreender as implicações políticas do tipo de trabalho que realiza, Ana Paula procura respaldo em referências de feministas negras da literatura contemporânea.

7 A vergonha e o constrangimento têm sido interpretados por autores como Norbert Elias (1993) e Erving Goffman (2012) como sentimentos que encadeiam aspectos psicológicos e sociológicos presentes nas interações sociais. Goffman, por exemplo, descreve o constrangimento social a partir de suas diferentes dimensões, desde seus sinais físicos objetivos até os sintomas subjetivos, ressaltando distintos níveis de emoções dolorosas que advêm de tais experiências, que vão do mero embaraço à vergonha e à humilhação. Já Norbert Elias define a vergonha como um sentimento de ansiedade e medo de degradação social que surge frequentemente diante de situações em que a pessoa se encontra impotente e frágil diante da suposta superioridade dos outros. Ambos os autores entendem tais sentimentos como aspectos que denotam a sensação de inferioridade social e que possuem características específicas em cada momento histórico, segundo seus contextos particulares. 
Eu acho que não dá para desassociar o movimento negro do movimento feminista. Na verdade, quem me apresentou mesmo o feminismo foi a Chimamanda Adichie. Eu não tinha referências, não achei livros de moda afro. Então comecei a ler outras referências para me fundamentar na moda. Acho que tem a coisa de um processo de liberdade. Quando as mulheres chegam aqui, elas tiram a máscara mesmo. Aqui é um lugar onde elas podem falar sobre o corpo delas sem receio de não serem acolhidas. Aqui elas não precisam ter vergonha de pedir o tamanho da roupa delas.

As experiências narradas e traduzidas pela empresária em termos que expressam emoções e sentimentos nos permitem perceber como processos de afirmação política vivenciados por mulheres negras encontram-se intimamente ligados a uma necessidade de recomposição de sua autoimagem, através de um caminho subjetivo, íntimo, ao mesmo tempo que coletivo, de experiências estéticas fundamentais para a construção de novas formas de pensarem, de se identificarem, e também de se comunicarem. Tais dinâmicas coletivas, permeadas de um vocabulário emocional, constituem o que Clifford Geertz (2008) denominou, em seu célebre trabalho sobre a briga de galos balinesa, como formas de "educação sentimental", que seriam centrais na construção das subjetividades dos sujeitos implicados.

Desse modo, o ateliê Xongani torna-se pouco a pouco um espaço de reflexividade e de acolhimento de demandas, especialmente de um perfil de mulheres negras em fase de desenvolvimento profissional que encontram em tais mudanças estéticas, acompanhadas por um discurso autointitulado feminista, formas de comunicarem seu lugar político no mundo social. Nas palavras de Ana Paula:

Quando eu conheci o feminismo, quando eu me aproximei do feminismo, tem esse negócio da gente querer contar para o mundo. Contar para o mundo que agora eu descobri que eu sou uma mulher negra. E a moda é uma ótima ferramenta para a gente contar para o mundo. Então elas chegam assim: "Ana Paula, amanhã eu vou ter uma reunião com meu chefe e ele precisa entender quem eu sou. Você me veste? Ele precisa entender o que eu estou fazendo lá." “Me empoderei, eu estou estudando, me graduando, entrando no mestrado, no doutorado, consegui um cargo bacana. Eu sou uma professora e quero ser uma referência. Me ajuda a comunicar isso?" 
Através da moda e da estética, Ana Paula auxilia cuidadosamente mulheres negras em suas diferentes necessidades a se reconhecerem, desconstruindo os paradigmas de beleza em torno do corpo branco, bem como os "sentimentos de desajuste" por eles provocados, promovendo novas perspectivas e relações de pertencimento nas quais a noção de "empoderamento" passa a ser utilizada para descrever o sentido político de tais experiências que dizem respeito, sobretudo, a formas de produção de visibilidade (Scott, 1998). Nesse sentido, se a categoria "autoestima" permanece importante para a afirmação estético-política dessas mulheres, é a categoria "empoderamento" que nos permite perceber de que modo tais dinâmicas subjetivas convertem "sentimentos de desajuste", traduzidos em categorias como vergonha e constrangimento, em emoções positivas que se reconfiguram a partir de tais experiências coletivas de enunciação e que exprimem não só o desejo, mas, sobretudo, o bem-estar, o orgulho e o prazer na visibilidade.

O relato de Ana Paula nos permite apreender, portanto, dois processos interconectados. De um lado, as experiências que se dão por meio da expressão coletiva dos sentimentos e pela reformulação estética, traduzidas em empoderamento e autodefinidas como feministas; e, por outro lado, o papel de "mediação" (Velho, 2010) desempenhado por Ana Paula na proposição de tais dinâmicas que acontecem em seu ateliê, mas que se estendem em sua atuação através das mídias sociais. Entre as tantas funções que cumpre, como designer, empresária, militante e youtuber, é o fato de estar atenta às necessidades e especificidades desse sujeito em transformação que lhe permite articular saberes e afetividades aos produtos que vende.

Segundo Gilberto Velho (2010), o mediador é um intérprete capaz de transitar entre distintos grupos, códigos e redes sociais, não apenas on-line, mas também off-line, comunicando aspirações, questionamentos e dilemas aparentemente individuais, mas que contribuem para a construção coletiva de espaços renovados de partilha de significados, proposição de debates e mobilizações político-sociais. Nesse sentido, o sujeito da mediação pode ser uma ativista, uma artista, uma intelectual ou outro tipo de ator social que atue como um tipo de "agente de mudança" na recomposição contínua de formas democráticas de diálogo e criação de cidadania (Velho, 2010, p. 22).

Desse modo, o papel de mediadora que Ana Paula desempenha nos revela sua atenção tanto às mulheres que, sentindo-se em desajuste com seus corpos e sentimentos, procuram formas estético-afetivas criativas para se expressarem, quanto 
àquelas que já afirmam seu engajamento político e que, nesse espaço de partilha, sentem-se à vontade para escolher e demandar. E é essa liberdade que constitui também, na reflexão da empresária e comunicadora, a razão do sucesso da marca.

Eu sou pequena e ainda tem muita demanda a ser suprida. Era muita demanda, tudo acontecendo ao mesmo tempo, o cenário político mudando, a gente tendo acesso à universidade, às cotas, a lei 10.639, a questão do cabelo natural, as mulheres gordas, que também é outra pauta importante que a gente tem que cuidar. Temos que fazer numeração para todas as mulheres. Eu sempre pensei assim. Até porque, como a Xongani é muito empírica, tem muito essa coisa das pessoas chegarem e pedirem para fazer a numeração para elas. "Ah, Ana Paula, eu vou aí no seu ateliê, mas só se tiver minha numeração." Não tem mais como não contemplar as mulheres feministas, as mulheres gordas, as mulheres trans. Porque somos todas mulheres negras e elas não dão conta de serem excluídas de novo. Então a gente tem que abraçar muitas coisas e isso envolve todo um processo de pesquisa. Também acontece da parte das minhas clientes, tipo: "Ana Paula, essa é uma empresa feminista? Tem um lugar para eu trocar minha filha?" Aí a gente pensa na importância de estar atenta. A gente desconstruiu muitas coisas aqui no ateliê porque elas trazem.

O relato de Ana Paula revela, por fim, que seu trabalho se dá em um contexto de partilha de sentimentos e de demandas que anunciam um novo padrão de consumidora que se constitui no bojo das transformações vividas pelo país, particularmente, a partir da primeira década dos anos 2000 , como venho enfatizando. E é essa consumidora que buscará comunicar, como ela mesma diz, tais processos de mobilidade e de politização por meio de uma estética que lhe ofereça distintividade e explicite sua postura engajada. Desse modo, o mercado e o consumo adquirem particular relevância para as mulheres negras que constituem destacadamente seu público-alvo.

Enquanto as narrativas de Ana Paula elucidam dinâmicas que articulam emoções, corpo, afirmação identitária à produção de discursos sobre o feminismo, tendo seu ateliê como um espaço circunscrito e restrito às clientes que o visitam, é a loja virtual da marca que nos ajuda a observar de que maneira as novas mídias sociais adquirem um papel relevante nessa busca e também na construção de formas de representatividade. 


\section{Da literatura à novela global: o empoderamento como experiência}

No site oficial da marca Xongani, que dá acesso à loja virtual, é possível conhecer sua gama de produtos e efetuar compras sem sair de casa. Entre os produtos exibidos, como biquínis, maiôs e moletons, são os acessórios que protagonizam a página, com destaque para faixas de cabelo, cordões e brincos variados. Em meio a essa diversidade, alguns produtos recebem nomes em línguas africanas, enquanto outros recebem nomes de mulheres negras de destaque na mídia.

Nesse conjunto, dois itens despertam minha curiosidade por estarem relacionados a mulheres que Ana Paula havia mencionado em nossa conversa: o colar Ifemelu e os brincos Sheron, ${ }^{8}$ que remetem respectivamente à protagonista da obra literária Americanah, da romancista nigeriana Chimamanda Adichie (2014), e à atriz brasileira Sheron Menezzes. Representadas pelos acessórios Xongani, ambas as referências podem ser subentendidas como modelos de beleza e de afirmação identitária. No entanto, um olhar mais analítico para essas mulheres nos permite perceber uma gama de identificações mais profunda e reveladora.

Conforme narrei anteriormente, a admiração de Ana Paula pela escritora nigeriana tornou-se explícita quando mencionou seu livro Sejamos todos feministas. No entanto, o colar Ifemelu não carrega o nome da escritora, mas o de uma de suas personagens. Ifemelu é a protagonista de Americanah (Adichie, 2014), obra que narra a história de uma jovem nascida na Nigéria e que, em fins da década de 1990, em um momento de intensa turbulência político-econômica em seu país, emigra para os Estados Unidos em busca de melhores oportunidades para continuar seus estudos e iniciar sua vida profissional. Ao chegar aos Estados Unidos, a jovem se depara com uma série de estranhamentos culturais e sociais, e a questão racial, que até então nunca havia sido motivo de preocupação para ela, torna-se fonte de um intenso questionamento acerca de seu lugar na sociedade norte-americana. Nesse novo contexto, ela se vê pela

8 Links dos produtos: colar Ifemelu - http://xongani.com/produto/colar-ifemelu-6000/; brincos Sheron - http://xongani.com/categoria-produto/brinco/brincos-sheron/ (acesso em 09/04/2018). 
primeira vez como uma mulher negra e passa a ser interpelada por um conjunto de questões políticas que a confrontam cotidianamente.

Um exemplo contundente desses enfrentamentos ocorre quando, a certa altura, após já ter passado por algumas experiências de trabalho precarizado, ao receber um convite para fazer uma entrevista de emprego na área de relações públicas, ouve de uma amiga próxima: "Meu conselho? Tire essas tranças e alise o cabelo. Ninguém fala nessas coisas, mas elas importam. A gente quer que você consiga esse emprego" (Adichie, 2014, p. 220). Por não ser a primeira vez que ouvia tal recomendação, insegura com a advertência, embora se sentisse à vontade com seus longos cabelos trançados à mão, Ifemelu decide ir a uma profissional para desfazer suas tranças e alisar seus cabelos.

Nos dias que se seguem, como resultado do uso de um forte produto químico, grandes feridas começam a aparecer em seu couro cabeludo, provocando intensa dor e constrangimento diante da violência que havia imposto a si mesma. Com seus cabelos lisos, ela sente-se em luto. Abalada com sua nova aparência e com a falta de identificação consigo mesma, a jovem consegue $o$ almejado emprego, mas pede ajuda a uma conhecida que, contrária às técnicas de alisamentos, decide cortar seus cabelos deixando apenas dois dedos da raiz, livrando-a de todo o alisamento para que os mesmos possam crescer em sua forma natural. A mudança na aparência provoca um novo estranhamento, fazendo com que ela falte três dias seguidos em seu trabalho, alegando uma enfermidade.

O conflito com sua nova aparência persiste semanas a fio, até que uma outra amiga lhe indica um site de uma comunidade virtual, chamado FelizComEnroladoCrespo.com, contendo dicas e espaços de bate-papo para pessoas que estão passando pela experiência de retirada da química dos cabelos. A consulta ao site indicado permite, então, que Ifemelu mergulhe em um universo de dicas de beleza, indicações de produtos, técnicas de tratamento, variedade de cortes, configurando uma atmosfera de solidariedade entre mulheres negras que compartilham suas experiências e aprendizados. Através das redes sociais, a jovem nigeriana se dá conta de que, mais do que uma mera experiência estética, tais mulheres partilham de fato a construção política de uma experiência subjetiva, uma vez que, ao resistirem às imposições sociais de padrões rígidos de beleza com os quais não se identificam, atuam na formulação coletiva de novas interpretações de beleza e de feminilidade. 
Engajada com o processo de reformulação de seu cabelo, Ifemelu decide então iniciar um blog batizado Raceteenth, através do qual passa a dividir suas impressões acerca das relações raciais e da experiência de ser negra e africana - o que não é o mesmo que ser afro-americana - nos Estados Unidos. Com o sucesso de seu blog, que conta com milhares de acessos de diferentes partes do mundo, Ifemelu começa a receber apoio financeiro de leitores e anunciantes de sites de cosméticos, voltados para mulheres negras, até que, através de convites para dar palestras e financiamentos regulares, abandona seu emprego e começa a viver financeiramente de seu site pessoal.

O objetivo de narrar essa pequena passagem da trajetória da personagem Ifemelu é atentar para os processos de construção de um discurso feminista negro específico que se desenvolve através desse universo de sentimentos sobre o corpo, a estética e a afirmação identitária. Em seu ensaio "Alisando nuestro pelo", bell hooks (2005) chama atenção para o fato de que a construção coletiva de experiências afetivas em torno de percepções sobre os corpos e noções de beleza configura uma prática constitutiva da subjetividade política das mulheres negras. ${ }^{9}$ No caso de Ifemelu, tais experiências se intensificam marcadamente durante sua experiência de "transição capilar", quando a narrativa de inadequação e de sofrimento pelo uso intensivo de produtos químicos cede lugar à partilha de informações e sentimentos positivados, de autoapreço e autoconfiança, sobre os processos de crescimento dos cabelos em sua forma natural.

Se a dimensão de transformação estética está atrelada a uma transformação íntima, o papel das redes e mídias sociais intensifica consideravelmente o sentido coletivo de tais experiências. Assim, a narrativa ficcional de Americanah, embora diga respeito a um contexto aparentemente diverso do brasileiro, explicita um conjunto de questões que têm se tornado cada vez mais familiares às mulheres negras do país, ao retratar um processo de reformulação do olhar sobre si, que se dá coletivamente, sobretudo por meio das

9 É importante ressaltar que nos Estados Unidos os sentidos atribuídos aos processos de alisamento e uso dos cabelos em sua forma natural passam por distintas mudanças, vinculadas tanto às políticas raciais e às formas de militância, particularmente no decorrer da segunda metade do século XX, quanto às práticas de consumo (hooks, 2005). Desse modo, não é objetivo desse artigo fazer uma associação direta entre as experiências das mulheres afro-americanas e brasileiras, desconsiderando suas especificidades, mas demonstrar a relevância dessas redes de mulheres para o entendimento dos impactos do racismo em suas subjetividades, bem como para a criação coletiva de formas de combate à discriminação racial. 
mídias sociais, estimulando o consumo não só de produtos de beleza e de novas estéticas, mas de uma ampla gama de discursos feministas que circulam através dessas redes.

Um indício dessa ampla circulação de discursos aparece na constatação do crescimento do consumo de literatura feminista no país. Em 2017, uma matéria do jornal Folha de S. Paulo de título “Do comercial ao 'cabeça"' (Meireles, 2017), aponta o feminismo como o novo filão de apostas editoriais no mercado brasileiro enfocando as mulheres não só enquanto público-alvo, mas também enquanto autoras. De acordo com a reportagem, esse novo "produto de consumo" ganha destaque tanto pelo aumento expressivo na venda de livros de intelectuais clássicas do pensamento feminista, como a francesa Simone de Beauvoir - que teria vendido nos últimos três anos $35 \%$ a mais do que na década anterior inteira -, quanto de autoras contemporâneas, acadêmicas e/ou romancistas.

Entre as autoras negras estrangeiras, há dois destaques. Angela Davis, filósofa e ativista afro-americana que marcou a década de 1970 com sua atuação no Partido das Panteras Negras, e cujos livros, escritos durante a década de 1980, têm sido só recentemente traduzidos para o português. E Chimamanda Adichie, romancista nigeriana premiada, cujo último livro lançado, de título Para educar crianças feministas, figurou entre os primeiros no ranking de obras de não ficção mais lidas no país.

O destaque do mercado editorial para o consumo de produtos que tratam da temática do feminismo, e mais precisamente de autoras negras feministas, nos permite perceber as conexões dessas mulheres em um ambiente global de circulação e intercâmbio de ideias, interpretações e vocabulários através dos quais emerge uma nova gramática que diz respeito à construção de moralidades e subjetividades, lançando vistas à circulação de um novo sujeito político que marca sua presença não só nas redes sociais, mas, sobretudo, como venho enfatizando, na universidade.

Enquanto a homenagem de Ana Paula à Chimamanda Adichie se dá por iniciativa própria, ao nomear um de seus produtos com o nome Ifemelu, a menção à Sheron Menezzes nesse escopo de acessórios de moda acontece pelo contato da própria atriz com o ateliê, quando a mesma realiza uma encomenda de alguns produtos Xongani para a composição de Paula, personagem encenada na novela Babilônia, exibida em horário nobre na Rede Globo, em 2015. Acontecimento que provoca um verdadeiro boom de vendas e de publicidade da marca. 
No site da Rede Globo, a personagem Paula é descrita da seguinte maneira:

Advogada no escritório de Teresa, amiga de Regina. Bonita, atraente e muito sensual, é uma mulher moderna, independente, muito bem-sucedida. De origem humilde, nascida e criada no morro da Babilônia, passou para a faculdade pelo sistema de cotas e trabalhou muito para chegar onde está. ${ }^{10}$

A despeito da flagrante erotização que molda a personagem, explícita nos adjetivos que a descrevem como "atraente e muito sensual", ao destacar seu impacto em termos de representatividade da mulher negra na televisão, Ana Paula enfatiza o fato de Paula representar uma mulher negra bem-sucedida, subvertendo os estereótipos comuns que frequentemente associam a imagem das mulheres negras na mídia a posições sociais de subalternidade. Assim, é interessante o fato de que a personagem se destaca por uma trajetória de ascensão social que se dá pelo acesso ao ensino superior, pelo sistema de ações afirmativas, e que culmina em seu sucesso profissional, fatos que, segundo Ana Paula, promoveriam a identificação imediata de suas clientes.

Desse modo, o ganho de visibilidade da Xongani não se dá apenas pelo fato de haver uma atriz "global" utilizando seus produtos na novela, mas pelo fato de se tratar de um exemplo de trajetória bem-sucedida. Os aspectos estéticos da personagem também têm grande relevância, especialmente pelo uso do "cabelo natural" e da "moda afro", signos políticos de seu "empoderamento", e que estimularam a identificação imediata de diversas mulheres que estariam atravessando as mesmas mudanças estruturais. Em suas palavras:

Ela não era só uma atriz negra na novela, ela era uma advogada. Empoderada. Autossuficiente. Bem-sucedida. Emergente também, como nossa maioria que é classe C. Então ela nos representava de verdade. Ela tinha cabelo natural e usava moda afro. E aí você não tem noção da loucura que foi a Sheron Menezzes na novela. A questão é que ela era uma advogada gata e minhas clientes começaram a mandar fotos comparando elas com a Sheron. Aí aconteceu um boom para a Xongani.

10 Cf. http://gshow.globo.com/novelas/babilonia/personagem/paula/ (acesso em 11/04/2018). 
Embora não seja o objetivo desse artigo fazer nenhum estudo de recepção, ou fazer qualquer debate sobre o enredo e as mensagens veiculadas pela trama de Babilônia, o relato de Ana Paula nos permite atentar para um viés da questão da busca por representatividade que diz respeito à relação entre mídia, telenovelas e consumo. Dimensão reveladora devido ao potencial desses veículos tanto de estímulo à formação de novas sensibilidades e subjetividades (Abu-Lughod, 2003) quanto de promoção de uma cultura do consumo (Almeida, 2007).

Entendendo a mídia como uma "tecnologia de gênero" (De Lauretis, 1994), ou seja, como um mecanismo social que atua na produção de representações, de práticas e de discursos que reproduzem visões normativas de gênero, Heloísa Buarque de Almeida (2007), ao tomar como objeto de análise a relação entre o campo publicitário e as novelas da Globo, chama atenção para duas questões: o fato de que o meio publicitário se apropria de bens culturais e de elementos simbólicos supostamente já presentes no imaginário e no cotidiano de seu público-alvo, as camadas médias e populares, de maneira a estimular e reforçar comportamentos de consumo; e o fato de que as novelas são pensadas no meio industrial e publicitário como um produto especificamente feminino, sendo suas tramas centradas em personagens femininos e dirigidas, particularmente, às mulheres.

Assim, a personagem encenada por Sheron Menezzes, embora ainda esteja atrelada a um tipo ideal de beleza negra, marcado pela sensualidade, bem como a um padrão normativo de feminilidade, nos ajuda a perceber como as mudanças político-econômicas do país enunciam novos sujeitos em termos de consumo e de cidadania que, para serem estimulados pelos meios publicitários e televisivos, precisam cada vez mais se ver representados de acordo com seus contextos. Nesse sentido, Paula encena perfeitamente esse conjunto de transformações que anima o imaginário de um perfil de mulheres negras brasileiras que, desde o início deste século, viram aumentar suas possibilidades de acesso ao ensino superior e de atuação profissional.

Essa constatação nos ajuda a compreender o impacto provocado, conforme me relata Ana Paula, pela aparição da advogada Paula utilizando brincos e turbantes no horário nobre. Aparição que fez com que várias mulheres entrassem em contato com o serviço de comunicação da Rede Globo para saberem o nome da marca dos acessórios utilizados pela atriz. Dessa maneira, novas consumidoras chegaram até a loja virtual da Xongani, buscando em muitos casos os mesmos produtos utilizados pela personagem na novela, promovendo 
o reconhecimento da marca nas redes sociais e ampliando sua visibilidade inclusive em sites de busca como Google e YouTube, espaços nos quais Ana Paula já circulava através de seu canal.

É interessante notar que as narrativas de Ana Paula sobre seu trabalho no ateliê Xongani, que retratam a travessia emocional que estimula tais mulheres a se identificarem politicamente como "mulheres negras", configuram um processo que, embora esteja alicerçado em experiências de discriminação racial sentidas desde a infância, em diferentes situações de sociabilidade cotidiana, ganham maior ênfase nos momentos de formação universitária e de atuação profissional. Não é por acaso que a relação com a questão profissional esteja fortemente presente nas experiências das personagens Paula e Ifemelu, sendo centrais para estimularem uma reflexão em termos raciais e de gênero, mas também em termos de expectativa de mobilidade social, de fortalecimento da autoestima e de ocupação de novos espaços de enunciação política. ${ }^{11}$

Ao atentar, portanto, para os sentidos das referências de mulheres negras que dão nome aos produtos Xongani, minha intenção é mostrar que nem os relatos de constrangimento e inadequação, definidos aqui como "sentimentos de desajuste", nem as buscas dessas consumidoras por experiências afetivo-políticas correspondem a situações esparsas ou isoladas vivenciadas por Ana Paula e suas clientes. Antes, trata-se de referências que têm circulado de diferentes maneiras pelo imaginário de mulheres negras brasileiras que estão em busca de novas representações estéticas e de exemplos de trajetórias pessoais para se identificarem e se inspirarem. Há uma demanda que, como vemos, vai aos poucos estruturando a percepção e a produção da Xongani. E o fato de Ana Paula apresentar um discurso político, autointitulado feminista, instrumentalizado em sua fala como produtora de moda, amplia sua visibilidade entre mulheres que buscam esse duplo conteúdo estético-político da experiência do consumo engajado.

11 Uma matéria recente do periódico El País, de título "Estudantes negros enfrentam o racismo de professores e colegas em universidades" (Cavicchioli; Moreira, 2018), retrata as dificuldades de alunos negros e negras brasileiros, que entraram no ensino superior entre 2013 e 2015, beneficiados por políticas de cotas, e que têm sido alvo constante de racismo. Entre os inúmeros depoimentos dos estudantes, a matéria mostra como os cabelos constituem um dos principais alvos dessas agressões, o que nos dá uma dimensão da complexidade da ocupação desses espaços sociais, que exige desses sujeitos de direitos a construção de ferramentas subjetivas para se fortalecerem politicamente e permanecerem em tais instituições. Nesses processos, a questão da estética figura, portanto, como um recurso fundamental de resistência. 
Assim, os relatos de Ana Paula sobre os processos de constituição política de mulheres negras, que se dão por meio de experiências de transição não só capilar, mas de reformulação de um conjunto de "sentimentos de desajuste" em narrativas de "empoderamento", nos revela uma diversidade de sentidos que dizem respeito a conquistas pessoais, particularmente subjetivas, como ganho de autoconfiança e autoestima, mas, também, a conquistas profissionais. Desse modo, as narrativas pessoais ampliam os usos e sentidos que a categoria empoderamento vai absorvendo a depender de quem fala, onde e para quem. Ainda assim, uma dimensão dessa categoria subsiste a toda e qualquer significação concorrente, a dimensão da experiência de transformação, que precisa ser adquirida e relatada por meio de enunciados não somente verbais, mas corporais e performativos (Butler, 2017).

Segundo Avtar Brah (2006), a noção de experiência é um conceito-chave para o feminismo e está no cerne dos processos de construção da subjetividade para a compreensão do "lugar" de formação do sujeito. No processo de constituição política, portanto, muitos movimentos de mulheres atribuem centralidade às suas experiências pessoais com a finalidade de contestarem as relações assimétricas de poder que as cercam no cotidiano. É nesse projeto que o "pessoal" adquire relevância política, estimulando o reconhecimento público das opressões, a desconstrução de paradigmas e a possibilidade de ressignificação contínua de suas identidades e subjetividades. ${ }^{12}$ Desse modo, as experiências mediadas por Ana Paula acerca dos dramas vividos por suas clientes nos ajuda a deslocar tais práticas da dimensão privada para a arena política, onde as emoções, muitas vezes dolorosas, devem ser pensadas dentro de uma "economia de moralidades" (Lutz; White, 1986), e nesse bojo as novas mídias adquirem destacado impacto.

12 A atribuição de narrativas pessoais como ato político não é um consenso no debate feminista. Sara Suleri (1992), por exemplo, faz uma crítica a esse recurso argumentando que este teria a tendência de tomar a experiência subjetiva como uma forma de verdade objetiva, o que produziria outras invisibilidades ao mesmo tempo em que solidificaria novos essencialismos. Gayatri Spivak (2010) também discute essa natureza paradoxal das representações coletivas, alegando que o recurso essencialista seria, por um lado, uma forma de compensar injustiças históricas e definir agendas mais amplas de lutas políticas centradas nos sujeitos perpetrados por tais violências; mas que, por outro lado, seria também um modo de naturalizar os grupos estratégicos enquanto totalidades indiferenciadas. 


\section{Novos espaços de enunciação e uma linguagem política para o consumo}

No artigo "Mulheres em movimento", Sueli Carneiro (2003) ressalta a importância dos novos meios de comunicação para a afirmação positiva da população negra, atentando para o fato de que por meio dessas ferramentas diferentes gerações de mulheres têm renovado suas estratégias de mobilização e escopo de reivindicações sem, contudo, deslocar a relevância das antigas pautas. Essa reflexão caminha de encontro com os apontamentos de Sonia Alvarez (2014) sobre a ampliação das "teias político-comunicativas" que sinalizariam tanto uma multiplicação de feminismos populares quanto uma popularização do feminismo.

Um exemplo elucidativo da relação entre as novas tecnologias de comunicação e o alargamento dos espaços de enunciação para mulheres negras está na realização da Marcha do Orgulho Crespo, cuja primeira edição foi protagonizada na Avenida Paulista, na cidade de São Paulo, em julho de 2015, em referência também ao dia da mulher afro-latino-americana e caribenha. Idealizada e produzida pela produtora cultural Thaiane Almeida e a jornalista Neomisia Silvestre, em parceria com a consultora de marketing digital Nanda Cury, a iniciativa reuniu mulheres diversas com a promoção de oficinas de turbante, oficinas de maquiagem, a participação de empreendedoras negras, e também com debates sobre temáticas relacionadas à valorização dos cabelos crespos como forma de luta contra a discriminação e o racismo. ${ }^{13}$

Embora a marcha tenha se originado na cidade de São Paulo, sua ampla divulgação por meio das mídias sociais Facebook, Instagram e Twitter estimulou a mobilização de mulheres em todo o país. Nos anos seguintes, com a ampla circulação de imagens, textos e vídeos, o evento ganhou formatos em diversas capitais, articulando diferentes coletivos de mulheres. Com o sucesso dessa iniciativa que, segundo o site oficial, mobilizou mais de 1000 mulheres em sua primeira edição, em conjunto com a deputada Leci Brandão, foi elaborado um projeto que, sancionado pelo governo do estado, culminou na criação

13 Cf. http://orgulhocrespo.com (acesso em: 30/04/2018). 
da lei 16.682/2018, instituindo o dia 26 de julho como o Dia do Orgulho Crespo no Estado de São Paulo.

Em um dos textos fundamentais do pensamento pós-colonial, Gayatri Spivak (2010) questiona as possibilidades de comunicabilidade e de enunciação dos sujeitos subalternos, particularmente das mulheres. Sua indagação não se refere apenas à oportunidade de fala, mas à criação de condições de fala e de escuta através das quais os sujeitos subalternos possam construir espaços de enunciação para justamente questionarem o modo como são representados. Para Homi Bhabha (1998), o espaço de enunciação constitui, logo, um lugar fronteiriço que marca um momento de contestação das representações por meio de um discurso conflitivo que se dá de maneira instável, arbitrária e situacional, e que, ainda que não seja intrinsecamente subversivo e emancipador, configura um potencial de ruptura e de enfrentamento dos enquadramentos normativos da alteridade por meio da negociação dos sujeitos com novas formas de conhecimento.

Desse modo, é na ampliação dos espaços de enunciação e de busca por visibilidade que a dimensão de reformulação afetiva e discursiva sobre os corpos nos permite perceber a relevância política da moda e da linguagem estética sobre sujeitos que de fato têm vivenciado novas dinâmicas de mobilidade social. Ao vislumbrarem tais estruturas de invisibilidade (Scott, 1998), onde se veem sempre como minoria representativa, essas mulheres têm compreendido cada vez mais o potencial político de estimularem o olhar para novas referências de mulheres negras, olhar que se regula em grande medida através de dinâmicas de consumo, de bens materiais e simbólicos. E se a atenção às novas mídias torna-se uma estratégia bastante eficaz para a ampliação dos espaços de enunciação e diálogo, torna-se também uma ferramenta potente para a reformulação dos discursos de diferentes setores do mercado que, atentos à linguagem dos afetos que permeia tais processos de afirmação identitária, oportunamente tomam parte nesse diálogo engajado.

Em 2017, o Google BrandLab de São Paulo, programa que tem como objetivo construir estratégias de divulgação e impacto de marcas no meio digital, revelou que pela primeira vez no Brasil as buscas no Google por cabelos cacheados haviam ultrapassado as buscas por cabelos lisos. Entre os dados expressivos, coletados entre os anos de 2012 e 2015, o relatório destacou um crescimento de $232 \%$ nas buscas por cabelos cacheados e de $309 \%$ no interesse por cabelos afro, além do fato de que as buscas por transição capilar haviam crescido $55 \%$ 
nos dois últimos anos. A pesquisa ainda revelou que o perfil protagonista dessa mudança estaria na geração de mulheres entre 18 e 24 anos.

Divulgado na internet pela plataforma Think with Google, o documento intitulado "Dossiê BrandLab: a revolução dos cachos" explica que essa "tendência", antes considerada underground pelo mercado, seria hoje mainstream devido ao fortalecimento da "identidade negra e afrodescendente" no país, que adota os cabelos como "símbolo de amor próprio". Entre os dados que a pesquisa apresenta sobre o crescimento do interesse pelos cabelos crespos e cacheados nas buscas on-line, chama atenção a utilização de um tom político e emocional, reproduzido abaixo, que ressalta a mudança de comportamento das mulheres negras, enquanto consumidoras, como um caminho de fortalecimento de sua autoestima e de empoderamento político para a superação das experiências de racismo sofridas.

Quando a natureza das pessoas é transformada em motivo de vergonha e preconceito, abraçá-la se torna um ATO POLÍTICO. 1 EM CADA 3 MULHERES diz já ter sofrido preconceito por conta do seu cabelo. 4 em cada 10 já sentiram vergonha por ter cabelos cacheados. ABAIXO A DITADURA DO ALISAMENTO! (Dossiê..., 2017).

Ressaltando o YouTube como uma ferramenta central nos processos de busca de informações e na comunicação que se dá entre as mulheres que aparecem como porta-vozes dessas mudanças e que estão em busca de produtos e formas de tratamento, em um tom que combina um sentido de protesto com uma estratégia de marketing, a matéria anuncia: "As alquimistas estão chegando. E elas vêm trazendo para o YouTube técnica, estética, ética e várias misturinhas para deixar seus cachos poderosos com o que você tiver em casa." E afirmando que "a revolução será crespa", pergunta "como as marcas podem entrar nessa conversa?".

Atentando para os meandros de uma linguagem político-afetiva que se enuncia em meio às novas demandas por representatividade, se a pesquisa do Google BrandLab de São Paulo classifica as mulheres negras protagonistas de tais mudanças como "alquimistas", por conta da costura que têm operado entre as transformações identitárias recentes e as mudanças no padrão de consumo, é essa mesma linguagem que a pesquisa de mercado entende que necessita 
articular para capturar essa nova consumidora, e que se revela, portanto, de maneira perspicaz, em uma linguagem política para o consumo. ${ }^{14}$

Logo, parece-me importante lançar vistas para o modo como o mercado de consumo figura atento a um conjunto de movimentos que, ao que tudo indica, são expressivos de uma juventude negra que de diferentes maneiras têm conectado os campos da economia, da cultura e do engajamento político, incitando não só novos interesses de consumo, mas também uma nova forma de comunicação entre produto e consumidor. Assim, é seguro afirmar que em meio à multiplicação dos espaços de aparição e enunciação de mulheres negras, autodefinidas feministas, que atuam na absorção e amplificação de discursos sobre o corpo e sobre a valorização da beleza, um conjunto de saberes e de emoções são difundidos e dialogam diretamente, por meio das redes sociais on-line e off-line, com um mercado de consumo cada vez mais segmentado e amplo.

\section{Considerações finais}

Neste trabalho procurei contribuir para a compreensão de uma diversidade de atividades político-identitárias protagonizadas por mulheres negras, acompanhadas no cenário paulistano, sem perder de vista o alcance nacional dessas mediações, através das quais sujeitos variados identificam, em maior ou menor grau, a experiência do empoderamento com noções de pertencimento político, sucesso profissional, poder econômico, engajamento estético, entre outras que sigo interessada em mapear em minhas investigações atuais.

Pensar as perspectivas e demandas que delineiam esse sujeito, mobilizado em torno da categoria mulher negra, em relação a dinâmicas de consumo e às novas mídias sociais não constitui, evidentemente, uma tentativa de dar conta da complexidade de trajetórias, escolhas e embates que tais mulheres

14 Vale observar que o setor de cosméticos, particularmente de marcas que se tornaram populares e de grande apelo midiático, como Avon, Natura, O Boticário, em maior e menor grau, foi pioneiro nesse diálogo com outros perfis de consumidores, atentando para as diferenças não só em termos raciais. Contudo, o protagonismo dos cabelos crespos, observado no tema central da Marcha do Orgulho Crespo, bem como na pesquisa do Google, revela um contexto recente de práticas político-culturais que merece ser ressaltado. 
atravessam. Porém, minha reflexão busca apontar para alguns eixos desse emaranhado de discursos e práticas que envolve ações coletivas e afetividades.

Se os temas da representatividade, da estética, da autoestima e do consumo seguem tendo forte impacto político para a população negra, é necessário atentar para a pluralidade dessas mulheres, uma vez que os processos de autodefinição (Collins, 1990) que atravessam não implicam homogeneidade, mas diversidade na construção coletiva de significados. Nada indica, por exemplo, que as clientes da Xongani sejam em sua maioria leitoras de Chimamanda Adichie, ou, ainda, espectadoras das novelas da Rede Globo. Tampouco as mulheres negras que participam da Marcha do Orgulho Crespo podem ser entendidas como um grupo homogêneo. Do mesmo modo, o consumo dos produtos segmentados e o uso dos cabelos crespos não representam necessariamente uma afinação com as implicações políticas que tais estéticas promovem. Contudo, é inegável que em todos esses contextos a experiência em torno do corpo figura como um marcador de transformação e de valorização da beleza negra, de modo que os impactos subjetivos de tais práticas não devem ser subestimados.

Interpretar tais movimentos estéticos apenas sob o signo do consumo ou enfocar sua dimensão exclusivamente política nos impede de compreender a complexidade de estratégias e de demandas desses sujeitos em termos de direitos e de seus desejos de status, de ascensão social e de ocupação de espaços historicamente negados à população negra. Pois é nas tramas da violência e da desigualdade provocadas pela discriminação racial, que estruturam a sociedade brasileira e que se mantêm persistentes em nosso cotidiano, que está o cerne do sentimento de desajuste que nos acomete.

Consumo e política seguem experimentados através do corpo e traduzidos na forma de emoções e de sentimentos partilhados coletivamente reforçando a concepção feminista de que "o pessoal é político". E se corpo e emoções estão na ordem do político, o consumo torna-se um aspecto central na integração desses diferentes elementos de interação que revelam novos espaços de enunciação, de reflexão, e também de cooptação. Desse modo, tais dinâmicas indicam, sobretudo, itinerários de luta por visibilidade e por reconhecimento.

Por fim, é importante dizer que diferentes perfis de mulheres negras têm atuado fortemente contra os estereótipos discriminatórios e a invisibilidade, e têm conseguido construir maneiras próprias de aparição e de fala, tendo o corpo e a estética como canais expressivos dessa enunciação, como apresentado nos 
relatos de Ana Paula em seu ateliê, e apontado na Marcha do Orgulho Crespo. No entanto, há que se refletir a respeito do modo como o mercado das grandes marcas de fato "entra nessa conversa" e se apropria dessas narrativas políticas, enquanto estratégias de marketing, para agregar valor aos seus produtos, em detrimento de um contexto de desigualdades que atingem os produtores negros, e cujas demandas se mantêm em grande medida ofuscadas.

\section{Referências}

ABU-LUGHOD, L. Melodrama egípcio: uma tecnologia do sujeito moderno?. Cadernos Pagu, n. 21, p. 75-102, 2003.

ADICHIE, C. N. Americanah. São Paulo: Companhia das Letras, 2014.

ALMEIDA, H. B. de. Consumidoras e heroínas: gênero na novela. Estudos Feministas, Florianópolis, v. 15, n. 1, p. 177-192, 2007.

ALVAREZ, S. Para além da sociedade civil: reflexões sobre o campo feminista. Cadernos Pagu, n. 43, p. 13-56, 2014.

BHABHA, H. K. O local da cultura. Belo Horizonte: Ed. UFMG, 1998.

BRAH, A. Diferença, diversidade, diferenciação. Cadernos Pagu, n. 26, p. 329-376, 2006.

BUTLER, J. Introducción. In: BUTLER, J. Cuerpos aliados y lucha politica: hacia uma teoría performativa de la asamblea. Buenos Aires: Paidós, 2017. p. 9-30.

CARNEIRO, S. Mulheres em movimento. Estudos Avançados, v. 17, n. 49, p. 117-132, 2003.

CAVICCHIOLI, G.; MOREIRA, M. Estudantes negros enfrentam o racismo de professores e colegas em universidades. El País, 28 abr. 2018. Disponível em: https://brasil.elpais. com/brasil/2018/04/28/politica/1524918551_164874.html. Acesso em: 2 maio 2018.

COLLINS, P. H. The power of self-definition. In: COLLINS, P. H. Black feminist thought: knowledge, consciousness, and the politics of empowerment. New York: Routledge, 1990. p. 91-114.

DE LAURETIS, T. A tecnologia do gênero. In: HOLLANDA, H. B. (org.). Tendências e impasses: o feminismo como crítica da cultura. Rio de Janeiro: Rocco, 1994. p. 206-242.

DOSSIÊ BrandLab: a revolução dos cachos. Think with Google, jul. 2017. Disponível em: https://www.thinkwithgoogle.com/intl/pt-br/advertising-channels/vídeo/revolucao-dos-cachos/. Acesso em: 14 fev. 2018. 
ELIAS, N. Vergonha e repugnância. In: ELIAS, N. O processo civilizador. Rio de Janeiro: Jorge Zahar, 1993. 2 v. p. 242-248.

FIGUEIREDO, A. Beleza pura: símbolos e economia ao redor do cabelo do negro. 1994. Monografia (Graduação em Ciências Sociais) - Faculdade de Filosofia e Ciências Humanas, Universidade Federal da Bahia, Salvador, 1994.

FIGUEIREDO, A. Cabelo, cabeleira, cabeluda, descabelada: identidade, consumo e manipulação da aparência entre os negros brasileiros. 2002. Trabalho apresentado. XXVI Encontro Anual da Anpocs, Caxambu, 2002.

FRY, P. Estética e política: relações entre "raça", publicidade e produção de beleza no Brasil. In: GOLDENBERG, M. Nu e vestido: dez antropólogos revelam a cultura do corpo carioca. Rio de Janeiro: Record, 2007. p. 303-326.

GARCÍA CANCLINI, N. Consumidores e cidadãos: conflitos multiculturais da globalização. Rio de Janeiro: Ed. UFRJ, 2010.

GEERTZ, C. Um jogo absorvente: notas sobre a briga de galos balinesa. In: GEERTZ, C. A interpretação das culturas. Rio de Janeiro: LTC, 2008. p. 185-213.

GOFFMAN, E. Constrangimento e organização social. In: GOFFMAN, E. Ritual de interação: ensaios sobre o comportamento face a face. Petrópolis: Vozes, 2012. p. 95-109.

GOMES, N. L. Corpo e cabelo como símbolos da identidade negra. In: SEMINÁRIO INTERNACIONAL DE EDUCAÇÃO INTERCULTURAL, GÊNERO E MOVIMENTOS SOCIAIS, 2., 2003, Florianópolis. Anais [...] Florianópolis: UFSC, 2003.

HOOKS, b. Alisando nuestro pelo. La Gaceta de Cuba, n. 1, p. 70-73, enero-feb. 2005.

KOFES, S. Dossiê Gênero e Raça em revista: debate com os editores da revista Raça Brasil. Cadernos Pagu, n. 6-7, p. 241-296, 1996.

LIMA, L.; ORTELLADO, P. Da compra de produtos e serviços culturais ao direito de produzir cultura. Dados, Rio de Janeiro, v. 56, n. 2, p. 351-382, 2013.

LUTZ, C.; WHITE, G. The anthropology of emotions. Annual Review of Anthropology, n. 15, p. 405-436, 1986.

MEIRELES, M. Do comercial ao 'cabeça', editoras do país exploram livros feministas. Folha de S. Paulo, São Paulo, 8 abr. 2017. Disponível em: http://www1. folha.uol.com.br/ilustrada/2017/04/1873710-do-comercial-ao-cabeca-editoras-do-pais-exploram-onda-feminista.shtml. Acesso em: 6 mar. 2018.

NEGROS quase triplicam no ensino superior no Brasil em 10 anos. CEERT, 16 fev. 2016. Disponível em: https://ceert.org.br/noticias/educacao/10307/negros-quase-triplicam-no-ensino-superior-no-brasil-em-10-anos. Acesso em: 2 maio 2018. 
POCHMANN, M. O mito da grande classe média: capitalismo e estrutura social. São Paulo: Boitempo, 2014.

SANTOS, J. T. dos. O negro no espelho: imagens e discursos nos salões de beleza étnicos. Estudos Afro-Asiáticos, n. 38, p. 49-65, 2000.

SCOTT, J. A invisibilidade da experiência. Projeto História, v. 16, p. 297-325, 1998.

SILVA, G. M. da. Empreendimentos sociais, negócios culturais: uma etnografia das relações entre economia e política a partir da Feira Preta em São Paulo. 2016. Tese (Doutorado em Antropologia Social) - Faculdade de Filosofia, Letras e Ciências Humanas, Universidade de São Paulo, São Paulo, 2016.

SILVA, G. M. da. Cultura negra e empreendedorismo: sensibilidades políticas a reivindicações econômicas e o engajamento através do mercado. Anuário Antropológico, Brasília, v. 43, n. 1, p. 11-36, 2018.

SOUZA, J. Os batalhadores brasileiros: nova classe média ou nova classe trabalhadora?. Belo Horizonte: Ed. UFMG, 2012.

SPIVAK, G. Pode o subalterno falar?. Belo Horizonte: Ed. UFMG, 2010.

SULERI, S. Women skin deep: feminism and the postcolonial condition. Critical Inquiry, v. 18, p. 756-769, 1992.

VELHO, G. Metrópole, cosmopolitismo e mediação. Horizontes Antropológicos, Porto Alegre, ano 16, n. 33, p. 15-23, 2010.

YÚDICE, G. A conveniência da cultura: usos da cultura na era global. Belo Horizonte: Ed. UFMG, 2013.

Recebido: 29/05/2018 Aceito: 05/02/2019 | Received:5/29/2018 Accepted:2/5/2019 